\title{
Impact of tourism resource development based on low-carbon mode: a case study of Guizhou ethnic areas
}

Jie Su

\begin{abstract}
Background: As environmental issues become increasingly prominent, the implementation of the low-carbon mode has become the trend of future economic development. The implementation of a low-carbon mode in the tourism industry is conducive to the sustainable development of the industry, but at present the low-carbon development of China's tourism industry still faces many problems, especially in ethnic areas where tourism is more developed.

Results: Taking Guizhou ethnic areas as an example, this study estimated the carbon emissions of the Guizhou tourism industry from 2011 to 2015. It was found from the calculation of tourism consumption stripping coefficient that the total carbon emissions in 2011-2015 were 21.37, 25.43, 27.93, 29.51, and 30.03 million tons, showing a rapid growth trend, in which the tourism accommodation catering industry accounted for a high proportion.

Conclusions: Guizhou's carbon emissions are increasing year by year, and there are still many problems in realizing lowcarbon tourism. The low-carbon tourism mode needs to be established from aspects of government, tourism enterprises, and tourists. The rich tourism resources in minority areas should be fully utilized to realize the sustainable development of the tourism industry.
\end{abstract}

Keywords: Low-carbon mode, Tourism industry, Guizhou

\section{Introduction}

In response to the increasingly serious global climate warming and environmental problems, a wave of lowcarbon economic activity is emerging. In this case, the tourism industry as the most potential industry of lowcarbon transformation has great prospects for development (Luo and Zhang 2011). With the increasing of residents' disposable income and the deepening of China's opening to the outside world, the tourism industry is booming. Low-carbon tourism is the fundamental way to realize the sustainable development of the tourism industry, and it is also an inevitable choice (Tang et al. 2011; Yang 2010). The concept of "low-carbon tourism" was first proposed at the Copenhagen conference in 2009 (Zhao et al. 2015). The low-carbon tourism industry has great social value and economic significance (He and Wang 2014). Li et al. (2013) have evaluated the tourism industry from a

Correspondence: sjgufe@126.com

Guizhou University of Finance and Economics, Huaxi University Town, Huaxi District, Guiyang 550025, Guizhou, China low-carbon perspective, established a low-carbon tourism service efficiency model, and evaluated the carbon footprint of 29 scenic spots in Sichuan Province, suggesting that the government should coordinate the economic development and environmental protection of tourism areas to promote the stable development of tourism. He et al. (2014) took eco-agriculture tourism as the object, analyzed the necessity of developing low-carbon eco-agriculture tourism, and put forward some suggestions for the sustainable development of eco-agriculture tourism from the perspective of low carbon. Taking Qinghai Lake as an example, Li et al. (2012) analyzed the current problems of low-carbon tourism in Qinghai Lake from three aspects, tourism construction, management and tourist behavior and then they proposed to strengthen the low-carbon propaganda for tourists, win the government's policy support, and conduct business management in an environmentally friendly way. Jiao and Shi (2013) have studied the $\mathrm{CO}_{2}$ emissions of the tourism industry in Gansu province and found that the tourism industry in Gansu province has the characteristics of energy conservation and low 
carbon. They also found that tourism transportation had the highest carbon emissions, which is the key to energy conservation and emission reduction. Wu and Yuan (2012) proposed the method of building low-carbon tourist attractions from the perspective of low-carbon product design, low-carbon transportation, low-carbon accommodation, and other aspects. As a multi-ethnic province, Guizhou has rich tourism resources and great development value. Taking Guizhou province as an example, this study analyzed the carbon emissions of the tourism industry in Guizhou province from 2011 to 2015 and then briefly analyzed the advantage of establishing a low-carbon mode of the tourism industry in Guizhou. In order to promote the sustainable development of the tourism industry in Guizhou, this study put forward some suggestions for the construction of low-carbon tourism mode.

\section{Methods}

\section{Aim of study}

The low-carbon mode is a new type of economic development model and a trend of future economic development. It has become a strategic measure to cope with global warming and has attracted widespread attention from all over the world (Zhang et al. 2011). The low-carbon mode refers to the reduction of carbon dioxide and other greenhouse gas emissions through policy guidance, technological innovation, and changes in individual life behaviors under the joint efforts of the government, enterprises, and individuals to form a mode of economic development of low-carbon emission. The low-carbon mode can not only meet the needs of economic development, but also protect the environment. The low-carbon mode is mainly to achieve sustainable development by reducing resource waste and environmental pollution. It achieves the dual goals of economic development and environment protection through adopting carbon neutral technology for green development and improving resource utilization based on the principle of low energy consumption and high efficiency. On the issue of global warming, the tourism sector has generated about $5 \%$ of carbon dioxide emissions, and this number continues to increase as the tourism industry develops (Gössling et al. 2013). Incorporating the tourism industry into the scope of a low-carbon economy, building a low-carbon mode, and achieving green development will have a great impact on energy conservation, emission reduction, and environmental protection. At the same time, low-carbon tourism is the basis of the sustainable development of the tourism industry (Cui and Liu 2014). In order to achieve the long-term development of the tourism industry, we must adhere to the path of low-carbon mode.

\section{Analysis on the advantages of low-carbon tourism in Guizhou Superior natural conditions}

Guizhou's climate is warm and humid, suitable for living. The air quality is good, and temperature changes in Guizhou are small. It is warm in winter and cool in summer. The average temperature in summer is about $24^{\circ}$. The average temperature of Liupanshui, which is known as "China's cool capital", is as low as $19.8^{\circ}$. The annual average relative humidity is above $70 \%$. The ultraviolet intensity is low. The forest coverage rate in the province is about $40 \%$. Therefore, Guizhou is the best choice for a summer resort.

\section{Rich tourism resources}

Guizhou is a typical ethnic region. It is also a province with abundant tourism resources in China (Fig. 1), which has high tourism value. First of all, Guizhou has a typical karst landform. The landscape formed by this special landform is unique. The surface depressions and waterfalls are interlaced with underground caves and dark rivers which has an ornamental value. Secondly, Guizhou is a multi-ethnic province; the minority population accounts for about $40 \%$ of the province's total population. The mutual tolerance and collision of different ethnic cultures have gradually formed a colorful Guizhou culture. As an old saying goes, two places which have a distance of $1500 \mathrm{~m}$ may have different wind, and two places which have a distance of $5000 \mathrm{~m}$ may have different customs. Multi-ethnic culture has brought great influence to Guizhou's architecture, food, marriage customs, sacrifices, etc. Its complex and unique ethnic culture has also become a major feature attracting tourists. In addition, Guizhou has a rich historical and cultural background. From the Spring and Autumn Period and the Warring States Period to the founding of the People's Republic of China, Guizhou is always one of the important land. Besides Zunyi Meeting (an important conference for Chinese Communist Party, which was held in Zunyi, Guizhou, China) and crossing the Chishui River four times (a mobile warfare between the Red Army and National Revolutionary Army at the Chishui River basin at the boundary of Guizhou, Sichuan and Yunnan during the Red Army's long march) brought revolutionary colors to Guizhou culture.

\section{Calculation method of carbon emission of Guizhou tourism industry}

The carbon emission of tourism industry refers to the carbon emission generated in the process of energy consumption from the aspects of food, transportation, and accommodation involved in the tourism industry. Since there is no specific statistical project for the tourism industry's energy consumption in China, the tourism 


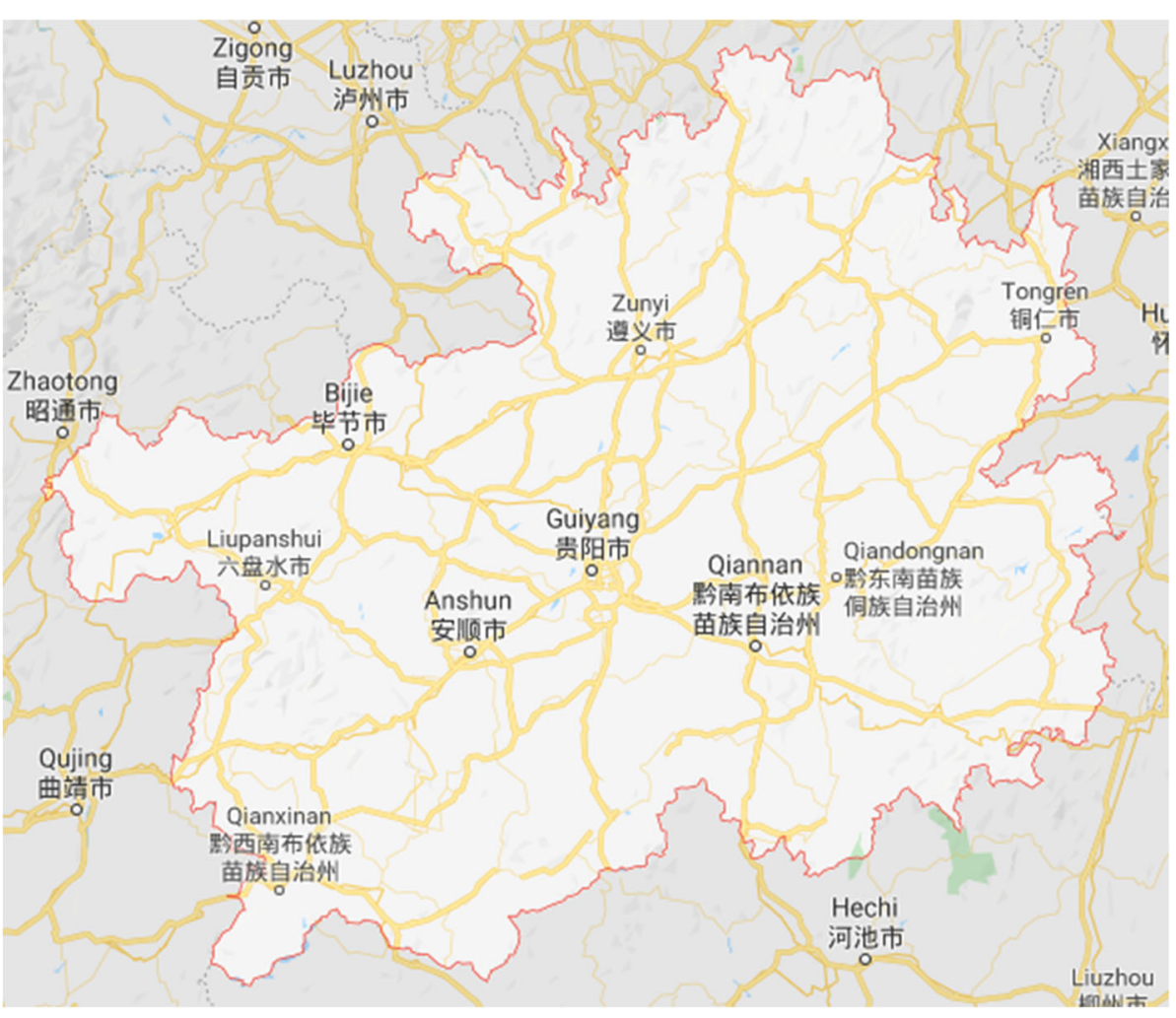

Fig. 1 Guizhou

consumption stripping ratio is used to calculate its energy consumption (stripping ratio is common in the mineral industry, and it is applied in the tourism industry here), that is to say (Abrishamifar 2005), the energy consumption of the tourism industry is separated from the energy consumption of its related industries, and the formula is as follows:

$$
A_{m}=\frac{T_{m}}{V_{m}},
$$

where $A_{m}$ stands for stripping ratio of tourism consumption of $m$ industry, $V_{m}$ stands for added value of $m$ industry, and $T_{m}$ stands for tourism added value of $m$ industry,

$$
\begin{aligned}
T_{m}= & \frac{m \text { industry added value }}{m \text { industry total ratio }} \\
& \times m \text { industry tourism total revenue. }
\end{aligned}
$$

The carbon emission of the tourism industry is the part generated by tourism in the total energy consumption of related industries. The calculation formula is as follows:

$$
\mathrm{TE}=\sum \mathrm{TE}_{m},
$$

where TE stands for the total carbon emissions of the tourism industry and $\mathrm{TE}_{m}$ stands for the carbon emissions from the tourism industry $m$.
The carbon dioxide emissions of the tourism industry are obtained by converting the energy consumed by the industry into standard coal. The calculation formula is as follows:

$$
\mathrm{TE}_{m}=\sum\left(E_{m n} \cdot k\right),
$$

where $E_{m n}$ stands for part of the $n$-type energy consumed by the industry $m$ related to the tourism industry and $k$ stands for the $\mathrm{CO}_{2}$ emission per unit of standard coal, 2.45 according to China's actual situation.

\section{Results}

\section{Data sources}

The relevant industries of tourism involve transportation, accommodation, catering, etc. The relevant data required in the calculation are all from the Statistical Yearbook of Guizhou Province and the China Energy Statistical Yearbook.

\section{Calculation results}

According to the total energy consumption of different industries in the Statistical Yearbook of Guizhou Province, the energy consumption of transportation, storage, postal, wholesale, retail, accommodation, and catering industries in ethnic areas of Guizhou from 2011 to 2015 is shown in Table 1. 
Table 1 Energy consumption (10,000 tons of standard coal)

\begin{tabular}{llllrr}
\hline & \multicolumn{1}{l}{ Year } & & & \\
\cline { 2 - 5 } & 2011 & 2012 & 2013 & 2014 & 2015 \\
\hline Transportation, storage, and postal industries & 597.73 & 610.45 & 665.41 & 711.87 & 778.50 \\
Wholesale, retail, accommodation, and catering industries & 554.60 & 783.17 & 831.99 & 816.29 & 1046.76 \\
\hline
\end{tabular}

The tourism consumption stripping ratio of ethnic areas in 2011-2015 was obtained according to the calculation formula of tourism consumption stripping coefficient, and the results are shown in Table 2.

As can be seen from Table 2, the tourism consumption divestiture coefficient of wholesale, retail, accommodation, and catering industries in ethnic areas was greater than that of transportation, storage, and postal industries, indicating that tourists had relatively high consumption in terms of food and shelter. In addition, the data on traffic and accommodation were growing year by year, indicating that the energy consumption of tourism-related industries is increasing with the development of the tourism industry.

According to Eq. 2, the carbon emission of Guizhou's tourism industry from 2011 to 2015 could be obtained, and the results are shown in Table 3 and Figs. 2 and 3.

As can be seen from Table 3 and Figs. 2 and 3, the carbon emissions of tourism in Guizhou's ethnic minority areas continued to increase from 2011 to 2015 and from 21.3721 million tons in 2011 to 30.03 million tons in 2015 and increased by about 10 million tons in 5 years. From the perspective of carbon emission composition, the carbon emission ratio of tourism, transportation, and postal service industry was gradually increasing, while the carbon emission ratio of tourism, accommodation, and catering industry was gradually decreasing, but it still occupied an important position. With the development of Guizhou's tourism industry year by year, the carbon emissions were also increasing, so it is an inevitable choice to build a low-carbon tourism mode.

\section{Discussion}

According to the calculation results, it was found that the carbon emissions in Guizhou were still increasing year by year. In order to achieve a sustainable development of tourism resources, a low-carbon model needed to be used. At present, there are still some problems between the low-carbon model and the development of tourism resources.
Low-carbon model requirement conflicts with industrial consumption demand

Tourist consumption is the driving force for the development of the tourism industry. On the one hand, higher consumption will bring more profits and plays a positive role in the development of the industry. On the other hand, tourists' consumption will also bring more problems, such as vehicle emissions and increased tourism waste.

\section{Higher cost to achieve low carbon mode}

At present, the development of China's tourism industry is still at the primary stage, and the main purpose is to improve the income. For ethnic areas, in order to achieve a low-carbon mode, there are high requirements on infrastructure construction, technical support, and personnel training. This is a large cost pressure for operators. At the same time, achieving a low-carbon mode may affect consumer experience to some extent, which may cause consumer resistance and result in low returns with high cost. To coordinate the contradiction between them, it is a big problem for operators.

\section{Lack of relevant institutional guarantees}

At present, the low-carbon mode is still in the initial development stage, and there is no clear regulation on the relevant legal system. In the process of tourism, tourists' awareness of environmental protection is weak. If they do not have enough knowledge to protect the environment and green travel, they will often have a great impact on the environment. Especially in ethnic areas, various ethnic cultural resources are relatively fragile and highly vulnerable to the outside world, which is difficult to control due to the lack of relevant systems. In addition, there is no clear institutional guarantee for clean energy, energy conservation, and emission reduction related to the low-carbon mode, which has caused great difficulties to the realization of the low-carbon mode.

Table 2 Stripping coefficient of tourism consumption

\begin{tabular}{llllll}
\hline & \multicolumn{3}{l}{ Year } & & \\
\cline { 2 - 5 } & 2011 & 2012 & 2013 & 2014 & 2015 \\
\hline Transportation, storage, and postal industries & 0.623191 & 0.625763 & 0.701251 & 0.725681 & 0.749082 \\
Wholesale, retail, accommodation, and catering industries & 0.901251 & 0.913206 & 0.914952 & 0.914603 & 0.935768 \\
\hline
\end{tabular}




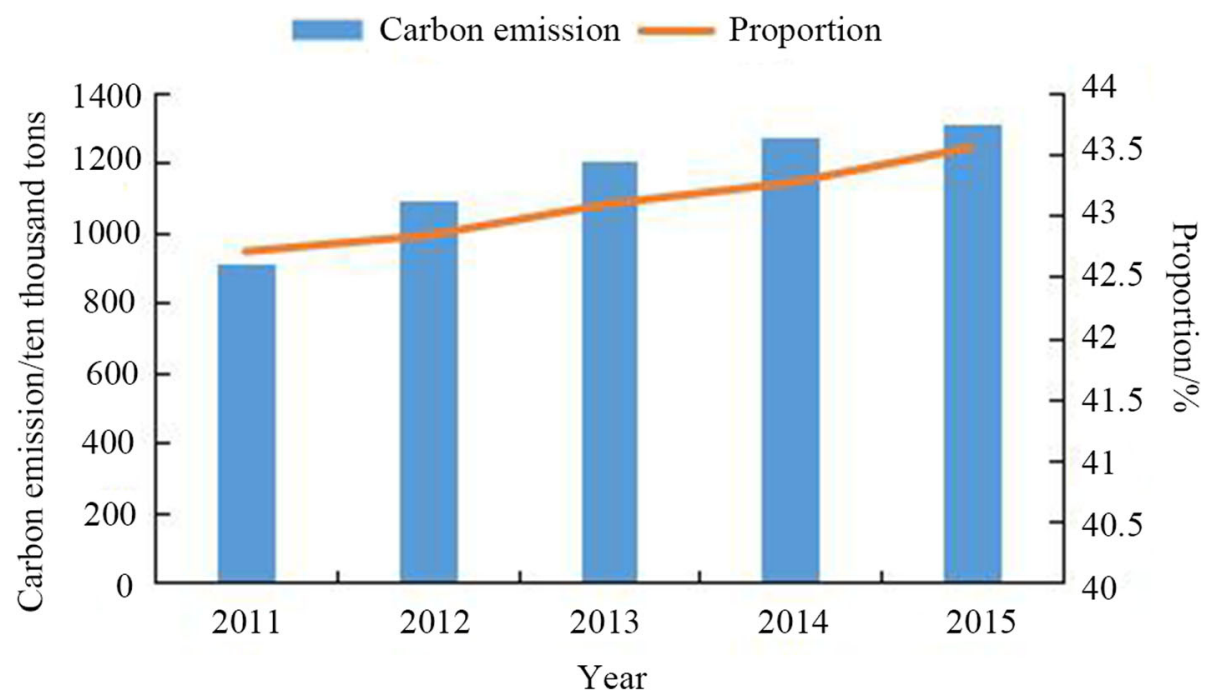

Fig. 2 Changes of carbon emissions of tourism transportation, storage, and postal industries

Government, tourism companies, and tourists are the three main objects in the construction of low-carbon tourism mode (Peng et al. 2014). To realize the development of low-carbon tourism resources of Guizhou, the low-carbon tourism mode needs to be established. When constructing the low-carbon tourism mode, it requires the joint efforts of all three parties and multiple channels to form a good development situation.

1. Government: plays a leading role in improving policies and regulations

The government plays a leading role in establishing a low-carbon tourism mode (Li et al. 2013). First, the government should introduce corresponding policies and regulations to encourage enterprises to build a low-carbon tourism industry, promote economic development while protecting national culture, and strengthen the promotion of lowcarbon tourism concepts to enhance the society's recognition of low-carbon tourism. The government should monitor the development situation at any time, constantly fine-tune the industrial layout, eliminate backward enterprises, support the development of advanced enterprises, promote strong alliances, and promote the sound and rapid development of low-carbon tourism.

2. Tourists: promote the concept of low carbon and strengthen the appeal of low carbon

Tourists are the main part of low-carbon tourism development. By promoting low-carbon concepts, tourists will agree with low-carbon tourism, which will generate low-carbon appeals, and this low-carbon appeal can drive the development of low-carbon products. The higher the demand for low-carbon tourism, the greater the desire to buy low-carbon products, the better the sales of low-carbon products, and the more promising the development of lowcarbon industries. In order to meet the low-carbon demands of tourists, enterprises will tend to produce low-carbon products that meet consumer needs, and low-carbon technologies will develop to form a virtuous circle.

3. Enterprises: adhere to the principle of low carbon and promote healthy competition When developing and building new projects, tourism enterprises should attach importance to energy conservation and emission reduction, adhere to the principle of protecting the environment, and

Table 3 Carbon emission of the tourism industry in Guizhou province from 2011 to 2015 (10,000 tons)

\begin{tabular}{|c|c|c|c|c|c|}
\hline & \multicolumn{5}{|l|}{ Year } \\
\hline & 2011 & 2012 & 2013 & 2014 & 2015 \\
\hline Carbon emissions of tourism transportation, warehousing and postal & 912.62 & 1089.25 & 1203.54 & 1276.83 & 1307.69 \\
\hline Ratio & $42.70 \%$ & $42.83 \%$ & $43.09 \%$ & $43.26 \%$ & $43.55 \%$ \\
\hline Carbon emissions of tourism wholesale and retail and accommodation catering & 1224.59 & 1453.69 & 1589.31 & 1674.62 & 1695.34 \\
\hline Ratio & $57.30 \%$ & $57.17 \%$ & $56.91 \%$ & $56.74 \%$ & $56.45 \%$ \\
\hline Total carbon emissions from the tourism industry & 2137.21 & 2542.94 & 2792.85 & 2951.45 & 3003.03 \\
\hline
\end{tabular}




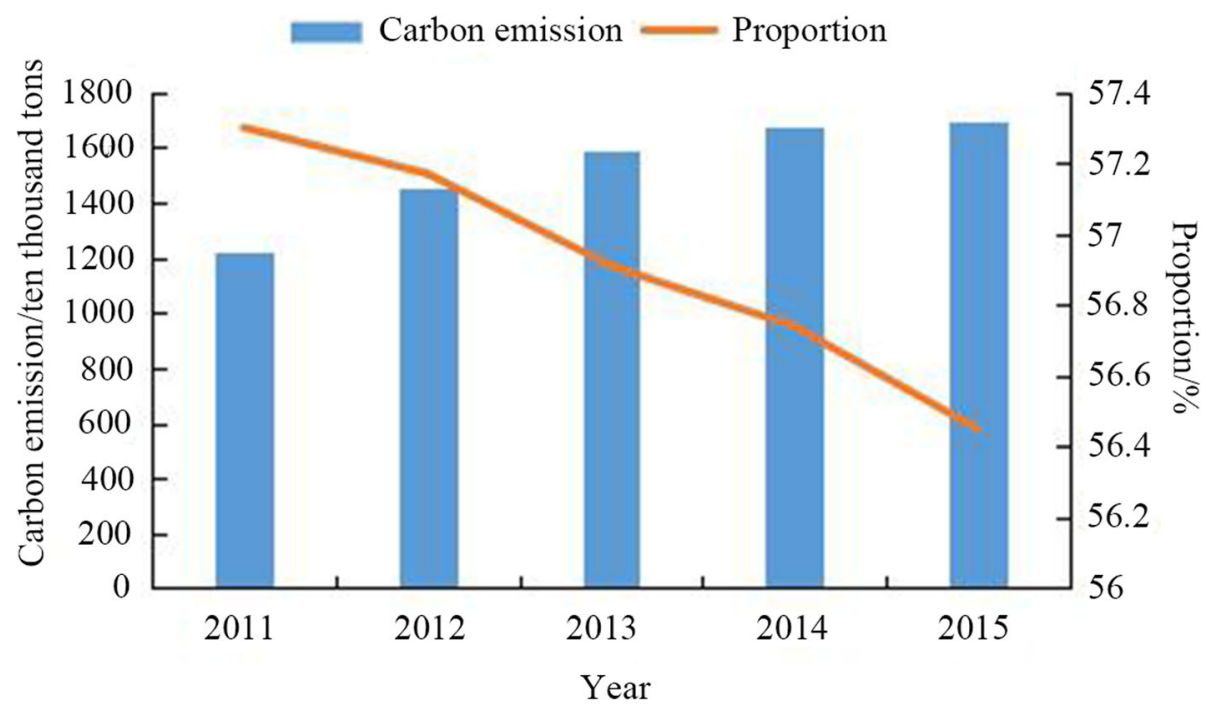

Fig. 3 Changes of carbon emissions of wholesale, retail, accommodation, and catering industries

realize the common development of economy and environmental protection. For example, when planning travel routes, arranging transportation, hotels, etc., we must fully reflect the low-carbon principle and aim to reduce the high-carbon behavior of tourists. We must make full use of resources, reduce unnecessary waste, and control greenhouse gas emissions during project construction to achieve a harmonious development of industry and environment.

Driven by profits and competition, low-carbon tourism companies in ethnic areas will continue to develop. In order to be able to share a piece of the market, each company must carry out continuous technological innovation and product research and development in order to survive in the everchanging competition. Advanced enterprises must maintain their advantages, and backward enterprises must get rid of the disadvantages, which will promote the enterprises to improve the quality of carbon products. Companies can get better development in such an environment.

\section{Conclusion}

With the emphasis on the environment, low-carbon tourism has received more and more attention. As a minority area, Guizhou has superior tourism conditions and has great advantages in developing tourism industry. Through calculating the carbon footprint of tourism in Guizhou tourism stripping coefficient, it was found that the number increased year by year, the proportion of carbon emissions in the transportation and communication industries is slightly increased, and the accommodation and catering industry still dominated. It indicated that we must start from these two aspects to achieve low-carbon tourism. The control of carbon dioxide emissions should focus on the government, tourism enterprises, and tourists. The government should dominate to encourage support for low-carbon tourism. Tourism enterprises should take efforts to develop low-carbon products and to strengthen the low-carbon concept education for tourists as the main body. With the joint efforts of multiple parties, building the low-carbon tourism industry of Guizhou with the rich ethnic tourism resources is just around the corner. This study makes some contributions to the development of Guizhou's tourism resources based on the low-carbon model, which is conducive to promoting the development of Guizhou's low-carbon tourism industry. However, due to the limited capacity, the research scope is relatively small. This study only analyzed the situation between 2011 and 2015, and the scope of the study needs to be expanded for further study.

Acknowledgements

Not applicable.

Availability of data and materials

All the data have been included in the article.

Author's contributions

The author read and approved the final manuscript.

Ethics approval and consent to participate

Not applicable.

Consent for publication

Not applicable.

Competing interests

The author declares that she has no competing interests.

\section{Publisher's Note}

Springer Nature remains neutral with regard to jurisdictional claims in published maps and institutional affiliations. 
Received: 3 April 2019 Accepted: 9 May 2019

Published online: 21 June 2019

\section{References}

Abrishamifar A (2005) Finding pushbacks in mine sections according to minimum stripping ratios. Mining Tech 114(2):99-106

Cui L, Liu H (2014) Study on the development of low carbon tourism in the era of low carbon economy. Adv Mater Res 962-965:2343-2346

Gössling S, Scott D, Hall CM (2013) Challenges of tourism in a low-carbon economy. WIRES Clim Change 4(6):525-538

He JB, Wang Z (2014) Research on low carbon transformation of tourism industry in China. Appl Mech Mater 651-653:1470-1473

He JB, Wang Z, Yin QL (2014) On sustainable development of eco-agricultural tourism in low-carbon economy. Adv Mater Res 869-870:946-949

Jiao BB, Shi PJ (2013) A rough estimation of energy consumption and $\mathrm{CO}_{2}$ emission in tourism of Gansu province based on low-carbon. Appl Mech Mater 316-317:435-440

Li JH, Sia R, Yang L (2012) Study on low-carbon development in the ecotourism area: taking Qinghai Lake of China as an example. Adv Mater Res 524-527:2442-2447

Li JH, Zhou RZ, Zhu YB (2013) Research on low-carbon tourism development in Qinghai province of China based on stakeholder theory. Appl Mech Mater 291-294:1429-1432

Li ZY (2013) The use of an efficiency evaluation method in the tourism service industry based on a low-carbon economy perspective. Tourism Tribune 28(10):71-80

Luo J, Zhang M (2011) Route choice of low-carbon industry for global climate change: an issue of China tourism reform. Energy Proc 5(3):2283-2288

Peng YD, Liu TT, Ji MT et al (2014) Research on development patterns of lowcarbon tourism in Qinhuangdao City. Appl Mech Mater 587-589:193-196

Tang Z, Shi CB, Liu Z (2011) Sustainable development of tourism industry in China under the low-carbon economy. Energy Proc 5(1):1303-1307

Wu QF, Yuan SL (2012) Low-carbon tourism scenic spots: background, concept and methods. Adv Mater Res 573-574:745-749

Yang W (2010) The development of tourism in the low carbon economy. Int Business Res 3(4):212

Zhang M, Luo J, Zhang X et al (2011) Study on low-carbon economy model and method of Chinese tourism industry. Int J Appl Logist 2(2):69-102

Zhao LM, Chen ZZ, Liu JY (2015) Evolutionary game theory between loca government and tourism enterprises in the context of a low-carbon economy. Tourism Tribune 30(1):72-82

\section{Submit your manuscript to a SpringerOpen ${ }^{\circ}$ journal and benefit from:}

- Convenient online submission

- Rigorous peer review

- Open access: articles freely available online

- High visibility within the field

- Retaining the copyright to your article

Submit your next manuscript at $\boldsymbol{\nabla}$ springeropen.com 